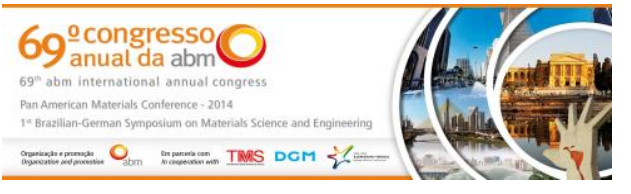

Tema: Metalurgia física e comportamento de materiais em temperaturas elevadas

\title{
EVOLUÇÃO ESTRUTURAL/COMPOSICIONAL DURANTE ENCHARQUE EM TRATAMENTO TÉRMICO DE RECOZIMENTO INTERCRÍTICO DE AÇO BAIXO CARBONO COM MICROADIÇÃO DE Mo E Nb*
}

\author{
Regis Antonio Albertassi Tavares ${ }^{1}$ \\ Andersan dos Santos Paula² \\ Fernando Generoso Neiva Ferreira ${ }^{3}$ \\ Rodrigo Rocha de Meira ${ }^{4}$
}

\section{Resumo}

O presente trabalho propôs-se avaliar a potencialidade de obtenção de uma microestrutura dual phase em um aço baixo carbono com microadição de molibdênio e nióbio, laminado a frio Full Hard. Os estudos foram suportados pelas análises da recristalização da ferrita, da fração volumétrica de austenita formada e sua evolução composicional/estrutural em função da temperatura de encharque no intervalo do campo intercrítico durante 0 encharque no tratamento térmico proposto com resfriamento em salmoura - a fim de simular o encharque no recozimento contínuo. As caracterizações microestruturais e mecânicas foram avaliadas por Microscopia Ótica, Microscopia Eletrônica de Varredura (MEV), Dilatometria e ensaios de dureza Vickers, e confrontadas com estudos prévios via Espectroscopia de Raios-X de Dispersão de Energia (EDS).

Palavras-chave: Bifásico; Aço baixo carbono com microadição de molibdênio e nióbio; Laminado a frio; Recozimento intercrítico.

\section{STRUCTURAL/COMPOSITIONAL EVOLUTION DURING INTERCRITICAL ANNEALING HEAT TREATMENT OF LOW CARBON STEEL WITH MO AND NB MICROADDITION}

\section{Abstract}

This present work aimed to evaluate the potential for obtaining a dual phase microstructure in a low carbon steel with molybdenum and niobium microaddition, cold rolled full hard. The study were explored by the ferrite recrystallization, the austenite formed volume fraction and compositional/ structural evolution as a function of soaking temperature on the intercritical range, during the soaking on the heat treatment proposed - to simulate the soaking in continuous annealing. The microstructural and mechanical characterizations studied were evaluated by optical microscopy, scanning electron microscopy (SEM), dilatometry and Vickers hardness tests, and compared with previous spectroscopy by Energy Dispersive X-ray (EDS) studies.

Keywords: Dual-phase; Low carbon steel with molybdenum and niobium microaddition; Cold rolled; Intercritical annealing.

1 Engenheiro de Produção, Mestrando da PPGEM, UFF, Volta Redonda, RJ, Brasil.

2 D.Sc., Engenheira Metalurgista, Professora Adjunta, EEIMVR, VMT e PPGEM, UFF, Volta Redonda, RJ, Brasil.

3 M.Sc., Engenheiro Metalurgista, Eng. de Desenvolvimento, CSN, Volta Redonda, RJ, Brasil

4 M.Sc., Engenheiro Metalurgista, Eng. Especialista de Desenvolvimento, CSN, Volta Redonda, RJ, Brasil.

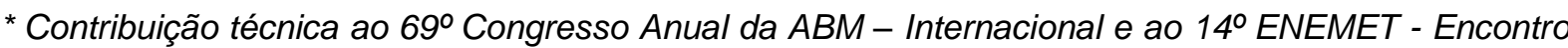
Nacional de Estudantes de Engenharia Metalúrgica, de Materiais e de Minas, 21 a 25 de julho de 2014, São Paulo, SP, Brasil.
} 


\section{INTRODUÇÃO}

Os aços baixo-carbono microligados vêm sendo utilizados para produção de aço ferrítico-perlítico com microestrutura duplex refinada. Um dos recursos disponíveis para se maximizar simultaneamente a ductilidade e resistência mecânica dos aços consiste no uso de microestruturas mais complexas do que ferrítica ou ferríticaperlítica, os aços bifásicos (dual-phase - DP) com microestrutura de matriz ferrítica com ilhas dispersas de martensita. A obtenção desta microestrutura nestes aços advém do resfriamento controlado a partir da região intercrítica o que lhes confere elevada resistência mecânica, boa tenacidade [1].

Faz-se presente no mercado aços DP laminados a quente e laminados a frio. Entre os laminados a frio, os aços DP têm demonstrado grande potencial de aplicação em veículos automotores [1]. Isto ocorre em razão destes materiais apresentarem amplo espectro de resistência mecânica, terem elevada ductilidade e capacidade de absorção de impacto e não apresentarem escoamento descontínuo. Com isto, esses aços conseguem atender aos vários requisitos impostos aos materiais, destinados as diversas finalidades.

O mecanismo de formação da austenita durante o tratamento térmico de recozimento no campo intercrítico destes aços (em particular do grupo de laminados a frio) é de considerável interesse, devido ao fato da resistência mecânica e da ductilidade, dos aços bifásicos, estarem diretamente relacionadas à fração volumétrica/distribuição das fases e porcentagem de carbono na fase martensítica.

Nestes aços, além do carbono, outros elementos de liga como o Mn e o Si têm um papel importante no controle da cinética das transformações de fase e em particular na estabilidade da austenita. Ambos os elementos aumentam a resistência do material através do endurecimento por solução sólida. O Mn pode substituir o $\mathrm{Fe}$ na formação de precipitados do tipo $(\mathrm{Fe}, \mathrm{Mn})_{3} \mathrm{C}$, e que podem dar origem a austenita rica em $\mathrm{Mn}$ que requer menor concentração de carbono para até mesmo se estabilizar a temperatura ambiente [2].

$\mathrm{O} \mathrm{Nb}$ é um elemento fortemente formador de carbonetos que atua como refinador de grão durante a etapa de laminação a quente e resfriamento controlado subsequente, e durante a recristalização na etapa de encharque durante o recozimento, que precede a laminação a frio. Durante as transformações da austenita em ferrita próeutetóide e para ferrita bainítica, a taxa de nucleação desses microconstituintes é muito aumentada, levando a um enriquecimento maior de $C$ na austenita remanescente nessas transformações, favorecendo a estabilidade da mesma. Bem como aumentando a temperabilidade desta austenita, possibilitando a formação do constituinte martensita de natureza adifisional durante o resfriamento controlado, no que diz respeito em particular ao processo de recozimento contínuo.

O presente trabalho tem por objetivo estudar a evolução microestrutural durante o encharque no campo intercrítico em um tratamento térmico de recozimento, em escala laboratorial (simulando o recozimento contínuo), que proporcione a recristalização e posterior resfriamento em salmoura, de modo que possa inferir na potencialidade de obtenção de uma microestrutura associada um aço dual-phase partindo de um aço baixo carbono com microadição de Mo e Nb laminado a frio FullHard. As caracterizações microestruturais e mecânicas das condições estudadas foram avaliadas por Microscopia Ótica, Microscopia Eletrônica de Varredura (MEV), Dilatometria e ensaios de dureza, e confrontadas com resultados de um estudo prévio com Espectroscopia de Raios-X de Dispersão de Energia (EDS). Neste estudo prévio, com uso de um EDS acoplado a um MEV FEG (Quanta 3D da FEI),

\footnotetext{
* Contribuição técnica ao $69^{\circ}$ Congresso Anual da ABM - Internacional e ao 14ํㅡㄹ ENEMET - Encontro Nacional de Estudantes de Engenharia Metalúrgica, de Materiais e de Minas, 21 a 25 de julho de 2014, São Paulo, SP, Brasil.
} 


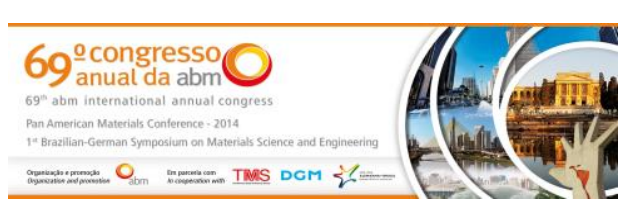

Ferreira [3] estimou a evolução do teor de C presente na austenita formada no encharque durante o recozimento intercrítico do aço objeto de estudo no presente trabalho, quando submetido a três distintas temperaturas de encharque e resfriamento em quatro meios distintos (salmoura, água a $80^{\circ} \mathrm{C}$, ar forçado e ar), conforme ilustrado na Figura 1. Em particular ao resfriamento em salmoura, pode-se verificar um expressivo decréscimo do teor de $C$ na martensita formada no resfriamento, a partir de temperatura de encharque de 750 e $800^{\circ} \mathrm{C}$. Enquanto os valores se mantiveram aproximadamente constantes para resfriamento em salmoura a partir de temperatura de encharque de 800 e $850^{\circ} \mathrm{C}$.

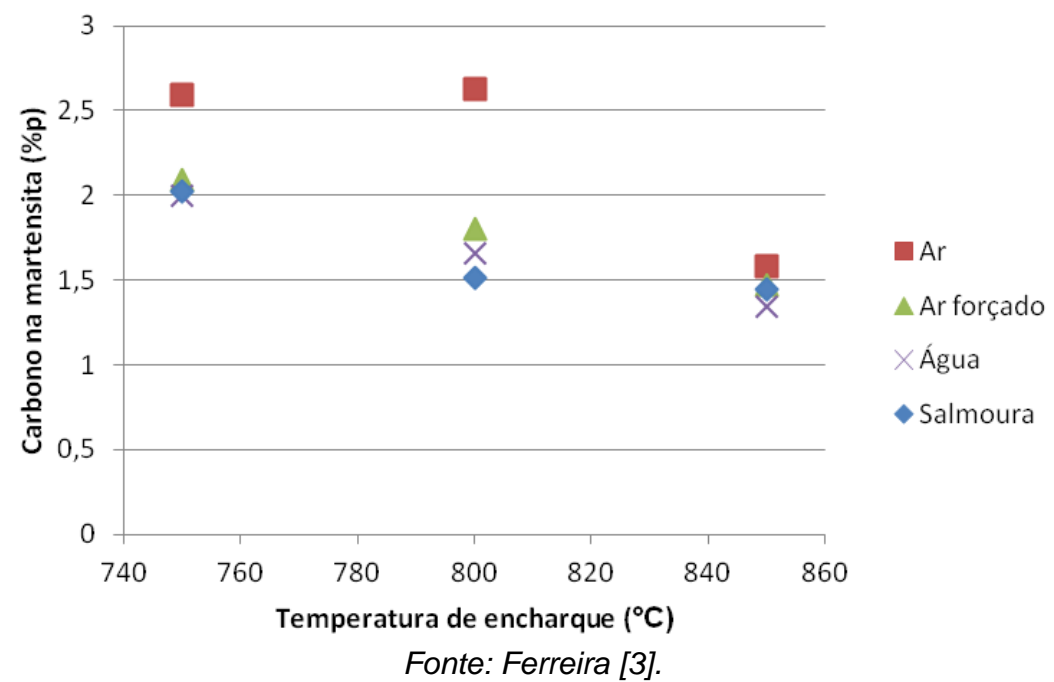

Figura 1. Estimativa da concentração de carbono na martensita, percentual em peso, para o aço em estudo [3].

\section{MATERIAL E MÉTODOS}

\subsection{Material}

O material em estudo é um aço de baixo carbono com a microadição de molibdênio e nióbio, o qual foi fornecido pela Companhia Siderúrgica Nacional (CSN - Volta Redonda / RJ, Brasil), proveniente de material laminado a quente $(3,5 \mathrm{~mm}$ de espessura) e posteriormente laminado a frio $(1,5 \mathrm{~mm}$ de espessura). As amostras para o estudo foram extraídas de chapa laminada frio full hard. A Tabela 1 mostra a composição química do aço em estudo com teores residuais de $\mathrm{Si}$, onde os percentuais dos demais elementos apresentam-se em faixas alargadas devido a exigências de sigilo industrial.

Tabela 1. Composição química do aço em estudo, percentual (\%) em peso.

\begin{tabular}{|c|c|c|c|c|}
\hline C & Mn & Mo & Al & Nb \\
\hline $0,075-0,105$ & $1,50-1,70$ & $0,14-0,24$ & $0,015-0,045$ & $0,012-0,021$ \\
\hline
\end{tabular}

Fonte: CSN - Companhia Siderúrgica Nacional.

\subsection{Métodos}

Inicialmente foram extraídas amostras de uma chapa de uma bobina a frio (BF) Full Hard, onde estas foram cortadas na forma de blanks, e posteriormente divididos em pequenas tiras de $300 \mathrm{~mm} \times 25 \mathrm{~mm}$ (DL - direção de laminação x DT) com 1,50 mm

\footnotetext{
* Contribuição técnica ao $69^{\circ}$ Congresso Anual da ABM - Internacional e ao 14ํㅡㄹ ENEMET - Encontro Nacional de Estudantes de Engenharia Metalúrgica, de Materiais e de Minas, 21 a 25 de julho de 2014, São Paulo, SP, Brasil.
} 


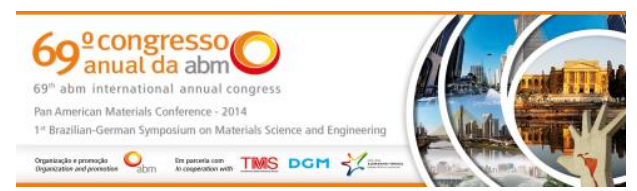

de espessura, de modo a possibilitar a retiradas de amostras para posterior análise microestrutural (microscopia óptica e MEV) e mecânica via medidas de dureza, nas condições posteriores aos tratamentos térmicos. Bem como separadas amostras sem tratamentos térmicos, condição laminada a frio Full Hard, para análise via dilatometria.

Tendo como base as temperaturas $A_{c 1} \approx 720^{\circ} \mathrm{C}$ e $A_{c 3} \approx 860^{\circ} \mathrm{C}$ (início e fim para transformação em austenita no aquecimento fora do equilíbrio) para o aço em estudo, calculadas por Ferreira [3] - segundo as equações (1) e (2) desenvolvidas, Trzaska e Dobrzanski [4], foram definidas as temperaturas de austenitização (encharque) nos valores de $710,720,730,740,750,760,770,780,790$, e $800^{\circ} \mathrm{C}$, e tempo de permanência de 180 segundos (simular ao tempo de encharque praticado no recozimento contínuo em escala industrial na CSN) e posterior resfriamento em salmoura. Estas temperaturas foram selecionadas de modo a se ter condições próximas ao início da transformação da perlita em austenita $\left(710,720\right.$ e $\left.730^{\circ} \mathrm{C}\right)$ ao redor da temperatura $A_{c 1}$ calculada. Enquanto a temperatura máxima $800^{\circ} \mathrm{C}$ foi definida com base nos estudos prévios de Ferreira [3], onde verificam uma possível inversão nos valores das propriedades mecânicas do aço dual phase em temperaturas entre 750 e $800^{\circ} \mathrm{C}$ para este mesmo aço em estudo.

$$
\begin{gathered}
A c_{1}\left[{ }^{\circ} \mathrm{C}\right]=739-22,8 \cdot \mathrm{C}-6,8 \cdot \mathrm{Mn}+18,2 \cdot \mathrm{Si}+11,7 \cdot \mathrm{Cr}-15 \cdot \mathrm{Ni}-6,4 \cdot \mathrm{Mo}-5 \cdot \mathrm{V}-28 . \mathrm{Cu} \\
A c_{3}\left[{ }^{\circ} \mathrm{C}\right]=937,3-224,5 \cdot \sqrt{\mathrm{C}}-17 \cdot \mathrm{Mn}+34 \cdot \mathrm{Si}-14 . \mathrm{Ni}+21,6 \cdot \mathrm{Mo}+41,8 \cdot \mathrm{V}-20 . \mathrm{Cu}
\end{gathered}
$$

Os tratamentos térmicos foram realizados no Centro de Pesquisa da CSN, para os quais foi utilizado um forno Brasimet do tipo Mufla, dotado de controlador digital de temperatura. De modo a poder-se ter o controle e registro da temperatura a que as amostras foram submetidas durante a etapa de tratamento térmico, foram utilizados termopares fixados a superfície das amostras tratadas. Amostras estas que foram inseridas na cavidade interna de um porta-amostra tendo o termopar junto a sua superfície, para em seguida serem inseridas no forno já aquecido na temperatura de encharque. De modo a garantir que a taxa de aquecimento fosse alta o suficiente de modo a simular o recozimento contínuo em escala industrial, onde as taxas de aquecimento praticadas para este tipo de material são de da ordem de $4^{\circ} \mathrm{C} / \mathrm{s}$ $\left(240^{\circ} \mathrm{C} / \mathrm{min}\right)$.

Com o intuito de observar as temperaturas associadas aos processos de restauração da estrutura deformada, por meio de recuperação e recristalização da mesma, e transformação de fase $\alpha \rightarrow \gamma$, bem como a influência de distintas taxas de aquecimento nestes fenômenos, foram realizados ensaios de dilatometria em um equipamento de análise termomecânica (TMA) da marca Shimadzu, modelo TMA60. Para assim comprovar que toda a modificação estrutural em estudo (recristalização e transformação de fase) deu-se somente na etapa de encharque nos tratamentos térmicos realizadas, ou seja, inibição destes fenômenos durante a etapa de aquecimento - caracterizando assim a configuração do recozimento contínuo. Os corpos de prova para estas análises tiveram dimensões aproximadas de $5 \times 5 \times 1,5 \mathrm{~mm}$, e foram imersos em uma solução de $50 \%$ de ácido nítrico $\left(\mathrm{HNO}_{3}\right)$ e $50 \%$ de ácido Fluorídrico (HF) durante aproximadamente 10 minutos, de modo a remover a camada encruada formada pelo corte de precisão em disco diamantado. Para tal ensaio, aqueceu-se corpos de provas do aço na condição laminada a frio Full Hard da temperatura ambiente até a temperatura de $900^{\circ} \mathrm{C}$ com duas taxas de

\footnotetext{
* Contribuição técnica ao $69^{\circ}$ Congresso Anual da ABM - Internacional e ao 14ํㅡㄹ ENEMET - Encontro Nacional de Estudantes de Engenharia Metalúrgica, de Materiais e de Minas, 21 a 25 de julho de 2014, São Paulo, SP, Brasil.
} 


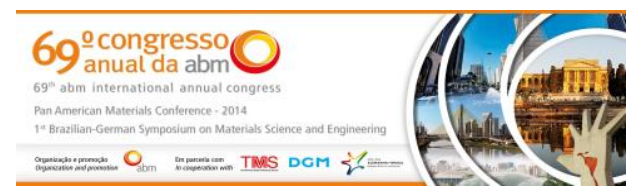

aquecimento distintas: $5^{\circ} \mathrm{C} / \mathrm{min}$ e aproximadamente $100^{\circ} \mathrm{C} / \mathrm{min}$, e posterior resfriamento natural.

A preparação metalográfica da superfície de análise, seção transversal associada a DL, foi nas seguintes etapas, após corte abrasivo e embutimento a quente: lixamento com lixas de carbeto de silício (220, 320, 500,600, 800, 1000 e 1200 mesh) e polimento com solução aquosa de alumina (1,0 $\mu \mathrm{m}$ e $0,5 \mu \mathrm{m})$.

$O$ ataque químico para revelar os microconstituintes formados sob as distintas temperaturas de encharque adotadas, nos tratamentos térmicos propostos, foi feita de duas formas distintas:

- Pré-ataque com Nital 3\% (3\% de ácido nítrico e 97\% etanol PA, em volume) com imersão por 2 segundos, e ataque com Picral 3\% (3\% de ácido pícrico e $97 \%$ etanol PA, em volume, solução envelhecida com sucata de aço por 24 horas) com imersão das amostras por 4 segundos. Com o intuito de quantificar a fração volumétrica de $2^{\underline{a}}$ fase (constituinte MA (martensita-austenita retida), perlita, bainita e carbonetos livres) via microscopia óptica, em um microscópio óptico Leitz no qual tem acoplado uma câmera digital controlada pelo software Analysis Pro para aquisição/tratamento de imagens, com uso da função Phases na ferramenta Materials Pro.

- Ataque com Nital 3\% com imersão da amostra por 7 segundos, com o intuito de análise detalhada da microestrutura via microscopia eletrônica de varredura, em um MEV, da marca Carl Zeiss / Modelo EVO MA10.

As medidas de dureza Vickers foram realizadas em um macrodurômetro (equipamento da marca Fritz Heckert), contando com um penetrador piramidal de diamante com base quadrada, aplicando carga de $100 \mathrm{kgf}$ e tempo de permanência de $20 \mathrm{~s}$, e com 20 medidas em posições aleatórias na superfície da chapa de cada uma das amostras submetidas aos tratamentos térmicos propostos neste estudo, inclusive a condição Full Hard.

Todos os equipamentos de análise envolvidos neste estudo estão instalados nos laboratórios da Escola de Engenharia Industrial Metalúrgica de Volta Redonda (EEIMVR) da Universidade Federal Fluminense (UFF).

\section{RESULTADOS E DISCUSSÃO}

Com base em trabalhos prévios foram realizadas análises relativas a evolução estrutural do aço em estudo ao longo das etapas de processamento prévia (Laminação a Quente e a Frio) ao recozimento contínuo para produção aço Dual Phase a partir de chapas laminadas a frio [3,5], representados na Figura 1.

A Figura 2 apresenta os resultados dos ensaios de dilatometria, com auxílio do equipamento TMA, na qual o aço em estudo, na condição laminada a frio full hard, foi submetido a um perfil de aquecimento contínuo da temperatura ambiente até $900^{\circ} \mathrm{C}$ sob taxas de aquecimento de aproximadamente 5 e $100^{\circ} \mathrm{C} / \mathrm{min}$.

Pode-se observar, como mostrado na Figura 2, o efeito do incremento da taxa de aquecimento em deslocar as temperaturas de recuperação, recristalização e transformação de fases $\left(A_{c 1}\right.$ e $\left.A_{c 3}\right)$ neste aço quando da condição inicial laminada a frio full hard $[6,7]$. Verifica-se com a taxa de aquecimento de $5^{\circ} \mathrm{C} / \mathrm{min}$ que o início da recuperação dá-se em $\approx 150^{\circ} \mathrm{C}$ (ponto 1 da Figura 2) e início da recristalização em $\approx 465^{\circ} \mathrm{C}$ (ponto 2 da Figura 2), enquanto para a taxa de aquecimento de $100^{\circ} \mathrm{C} / \mathrm{min}$ verifica-se o início da recuperação em $\approx 260^{\circ} \mathrm{C}$ (ponto $1^{\prime}$ da Figura 2 ) e início da recristalização em $\approx 707^{\circ} \mathrm{C}$ (ponto 2' da Figura 2). Porém somente na taxa de aquecimento de $5^{\circ} \mathrm{C} / \mathrm{min}$ pode verificar a reversão da transformação eutetóide

\footnotetext{
* Contribuição técnica ao 69ำ Congresso Anual da ABM - Internacional e ao 14ํㅡㄹ ENEMET - Encontro Nacional de Estudantes de Engenharia Metalúrgica, de Materiais e de Minas, 21 a 25 de julho de 2014, São Paulo, SP, Brasil.
} 
(pontos 3 e 4 da figura 2, sendo o início da reversão da transformação eutetóide, $A_{c 1 i}$ $\left(\approx 653^{\circ} \mathrm{C}\right)$ e o fim da reversão da transformação eutetóide, $A_{c 1 f}\left(\approx 735^{\circ} \mathrm{C}\right)$, respectivamente) e a completa transformação em $\alpha \rightarrow \gamma$ (pontos 5 e 6 da Figura 2, sendo o início da transformação $\alpha \rightarrow \gamma\left(\approx 802^{\circ} \mathrm{C}\right)$, e 0 fim da transformação $\alpha \rightarrow \gamma, \mathrm{A}_{c 3}$ $\left(\approx 872^{\circ} \mathrm{C}\right)$, respectivamente.
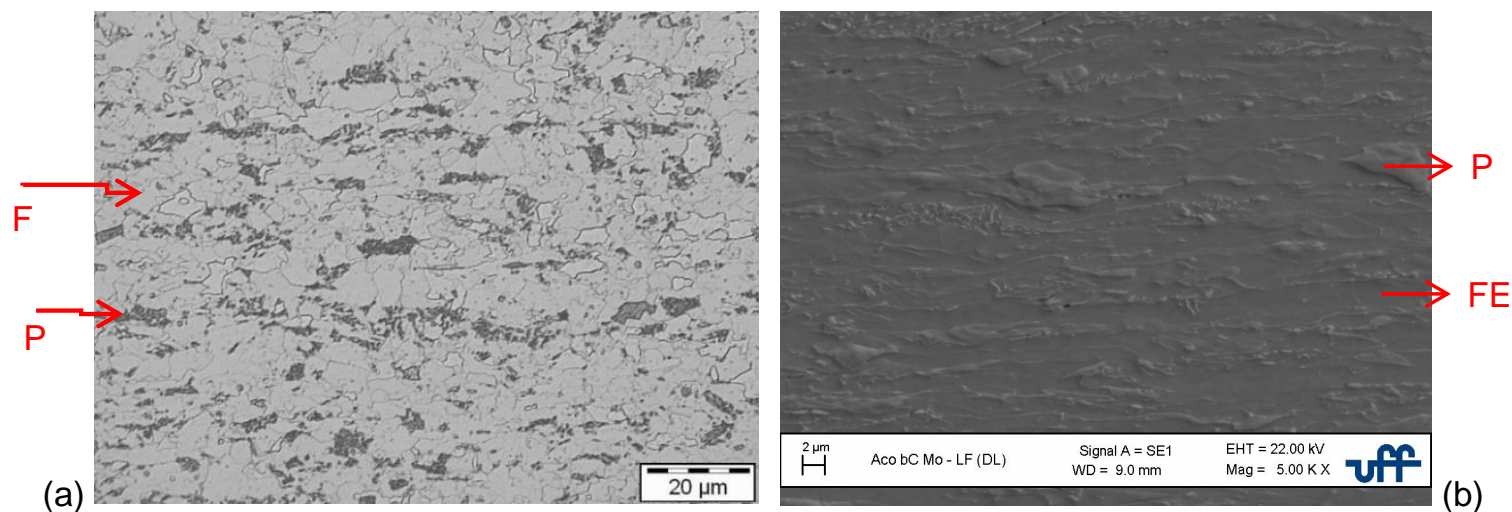

Fonte: Silva [5]

Figura 1. Aspecto microestrutural do aço em estudo na condição (a) laminada a quente e (b) laminado a frio, DL, processamentos prévios ao estudo proposto vinculado ao recozimento no campo intercrítico. Ataque: Nital 3\%. (a) MO - 1000X, F = Ferrita livre recristalizada (regiões claras); $P=$ Perlita (regiões escuras). (b) MEV - 5000x. FE = Ferrita encruada (baixo relevo); $\mathrm{P}=$ Perlita (alto relevo) [5].



Figura 2. Curvas relativas ao aço em estudo na condição laminada a frio full hard, quando submetido ao ensaio de dilatometria com ciclo de aquecimento da temperatura ambiente até $900^{\circ} \mathrm{C}$ com taxas de aquecimento de aproximadamente 5 e 100을 (inferiores as taxas adotadas nos tratamentos térmicos em estudo, em escala laboratorial, e recozimento contínuo em escala industrial). Indicando a ocorrência dos processos de: $\left(1,1^{\prime}\right)$ início da recuperação; $(2,2$ ') início da recristalização; $(3,4)$ Intervalo de início e fim de $A_{c 1}$; (5) Início da transformação $\alpha \rightarrow \gamma$; e (6) Fim da transformação $\alpha \rightarrow \gamma$, $A_{c 3}$.

Os comportamentos evidenciados nos resultados dos ensaios de dilatometria anteriormente apresentados e discutidos ajudam a suportar a hipótese que não há ocorrência de recristalização durante a etapa de aquecimento, que antecede o encharque, deste aço nas condições dos tratamentos térmicos adotados para o recozimento intercrítico. Tendo em vista que as taxas de aquecimento, praticadas no tratamento térmico em escala laboratorial (presente estudo) e no recozimento contínuo em escala industrial, são muito superiores (da ordem de $\left.4^{\circ} \mathrm{C} / \mathrm{s}\left(240^{\circ} \mathrm{C} / \mathrm{min}\right)\right)$ as adotadas nos ensaios de dilatometria realizados (5 e $100^{\circ} \mathrm{C} / \mathrm{min}$ ). Evidencias

\footnotetext{
* Contribuição técnica ao 69ํ Congresso Anual da ABM - Internacional e ao 14ํㅡㄹ ENEMET - Encontro Nacional de Estudantes de Engenharia Metalúrgica, de Materiais e de Minas, 21 a 25 de julho de 2014, São Paulo, SP, Brasil.
} 


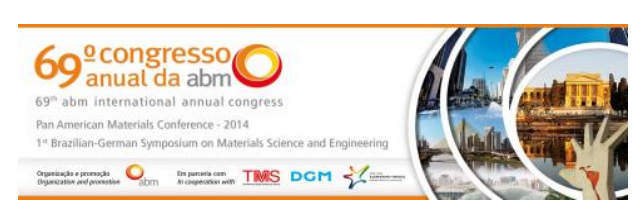

estas suportadas pela literatura [6-8], em que relatam que quanto maior a taxa de aquecimento adotada menor é o potencial termodinâmico para a recuperação da estrutura encruada e maior para a recristalização, aumentando assim a possibilidade do início e prosseguimento da recristalização durante o estabelecimento da temperatura de encharque no recozimento. Características básicas que diferenciam os fenômenos presentes e produtos resultantes de tratamentos térmicos de recozimento para recristalização em fornos de recozimento contínuo (altas taxas de aquecimento conjugadas a temperaturas de encharque mais elevadas associadas a tempos de encharque mais curtos) ao invés de em fornos de recozimento em caixa. Através da quantificação de fase das imagens obtidas via análise de $\mathrm{MO}$, verificouse que a fração da $2^{\text {a }}$ fase aumenta com aumento da temperatura de encharque em detrimento do decréscimo de fração de ferrita livre (encruada e recristalizada, percentual de percentual distinto em função da temperatura de encharque com permanência a 180 s), conforme o gráfico apresentado na Figura 3 revela.

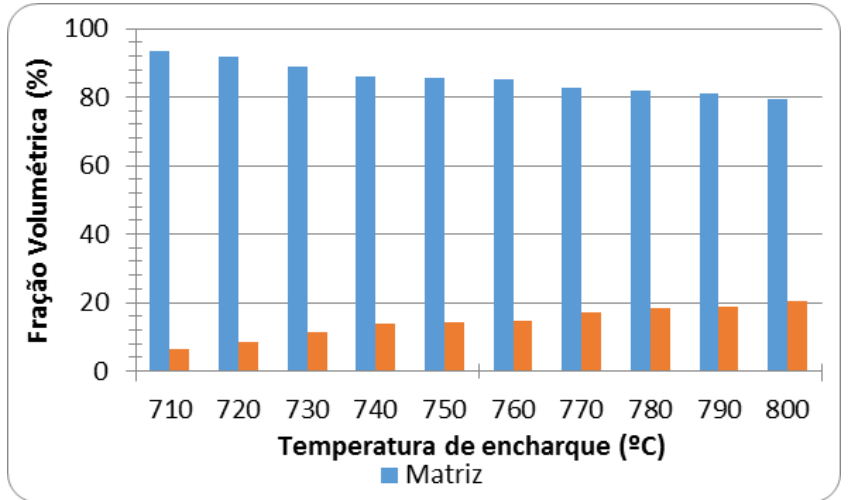

Figura 3. Quantificação de fases (ferrita - matriz / $2^{\mathrm{a}}$ fase) em função da temperatura de encharque adotada no tratamento térmico de recozimento no campo intercrítico para o aço em estudo.

Com base nas análises da microestrutura do material via $\mathrm{MO}$ e detalhamento das fases presentes via MEV, foi possível observar e definir a evolução estrutural associada ao processo de recristalização da ferrita livre encruada, resultante da laminação a frio, e os constituintes vinculados a $2^{\text {a }}$ fase presente / formada no encharque (temperatura máxima) durante o recozimento no campo intercrítico no intervalo de temperatura entre 710 e $800^{\circ} \mathrm{C}$ por 180 segundos, como é mostrado nas Figuras 4 a 6.

Pode-se observar inicialmente, nas temperaturas de encharque de 710 a $790^{\circ} \mathrm{C}$, a formação de segunda fase associada ao constituinte martensita-austenita (MA) e a manutenção de possíveis carbonetos no interior dos grãos de ferrita livre (Figuras 4, 5 e 6). Tendo em vista a composição química do aço em estudo e as temperaturas adotadas, os carbonetos podem estar associados ao Nb e/ou Mo [9]. Em paralelo a isso, verifica-se a gradual recristalização da ferrita durante a etapa de encharque, pelo aumento da fração aparente de grãos de ferrita livre recristalizada em detrimento da fração de grãos de ferrita livre encruada. No entanto, com o uso da temperatura de encharque de $750^{\circ} \mathrm{C}$ e manutenção por $180 \mathrm{~s}$, seguido de resfriamento em salmoura (Figura 5a), o constituinte MA formado passa a apresentar uma maior dimensão. Com o incremento da temperatura de encharque verifica-se um incremento contínuo da dimensão das regiões associadas ao constituinte MA, até a condição de encharque na temperatura de $800^{\circ} \mathrm{C} /$ manutenção por $180 \mathrm{~s}$ (Figura 6c), onde se verifica que a dimensão do constituinte MA aproxima-se da dimensão dos grãos de ferrita livre [3].

\footnotetext{
* Contribuição técnica ao $69^{\circ}$ Congresso Anual da ABM - Internacional e ao 14ํㅡㄹ ENEMET - Encontro Nacional de Estudantes de Engenharia Metalúrgica, de Materiais e de Minas, 21 a 25 de julho de 2014, São Paulo, SP, Brasil.
} 




(a)
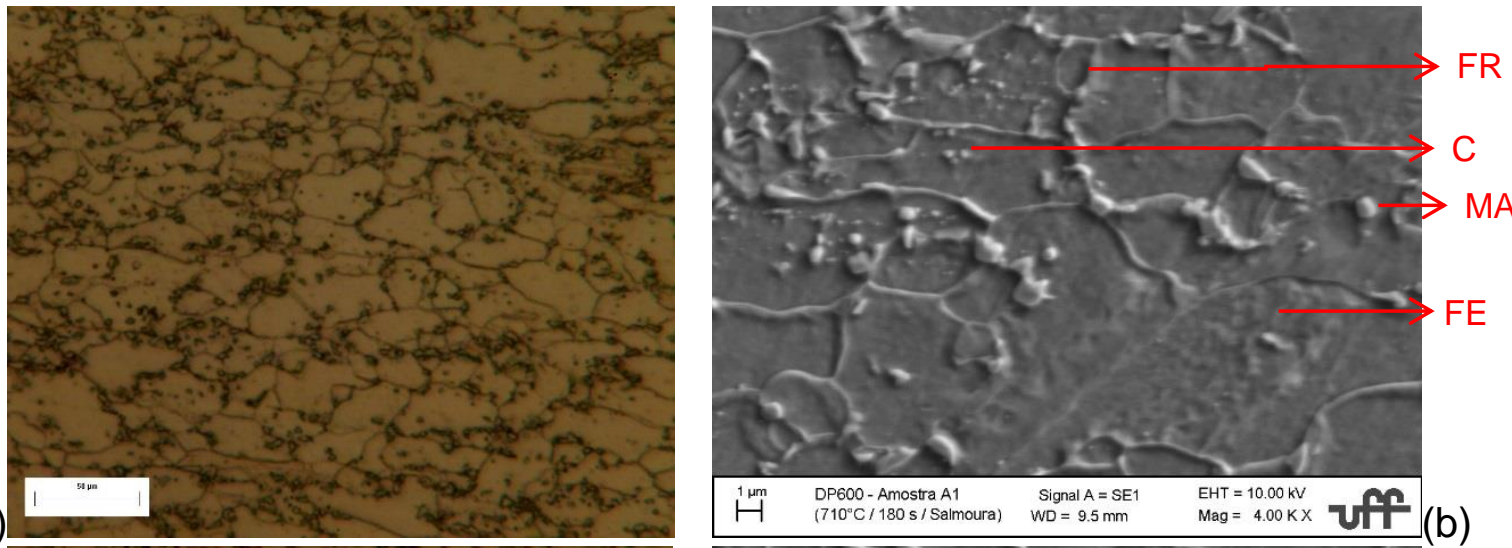

(c)
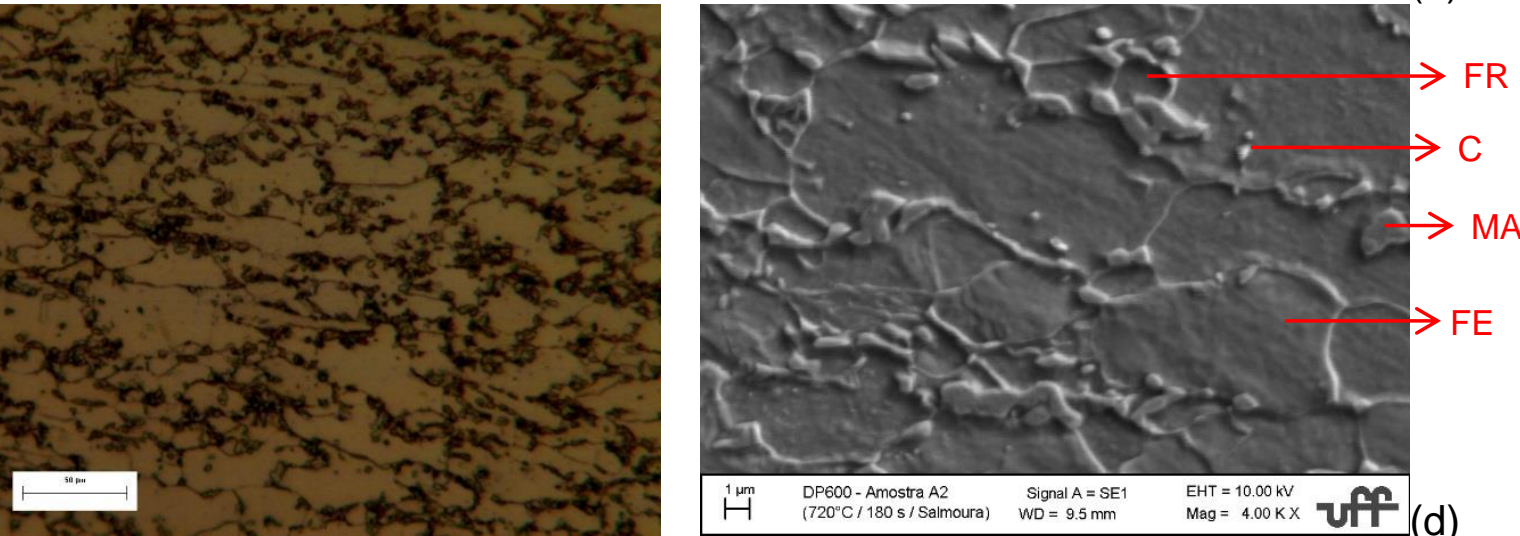

(e)
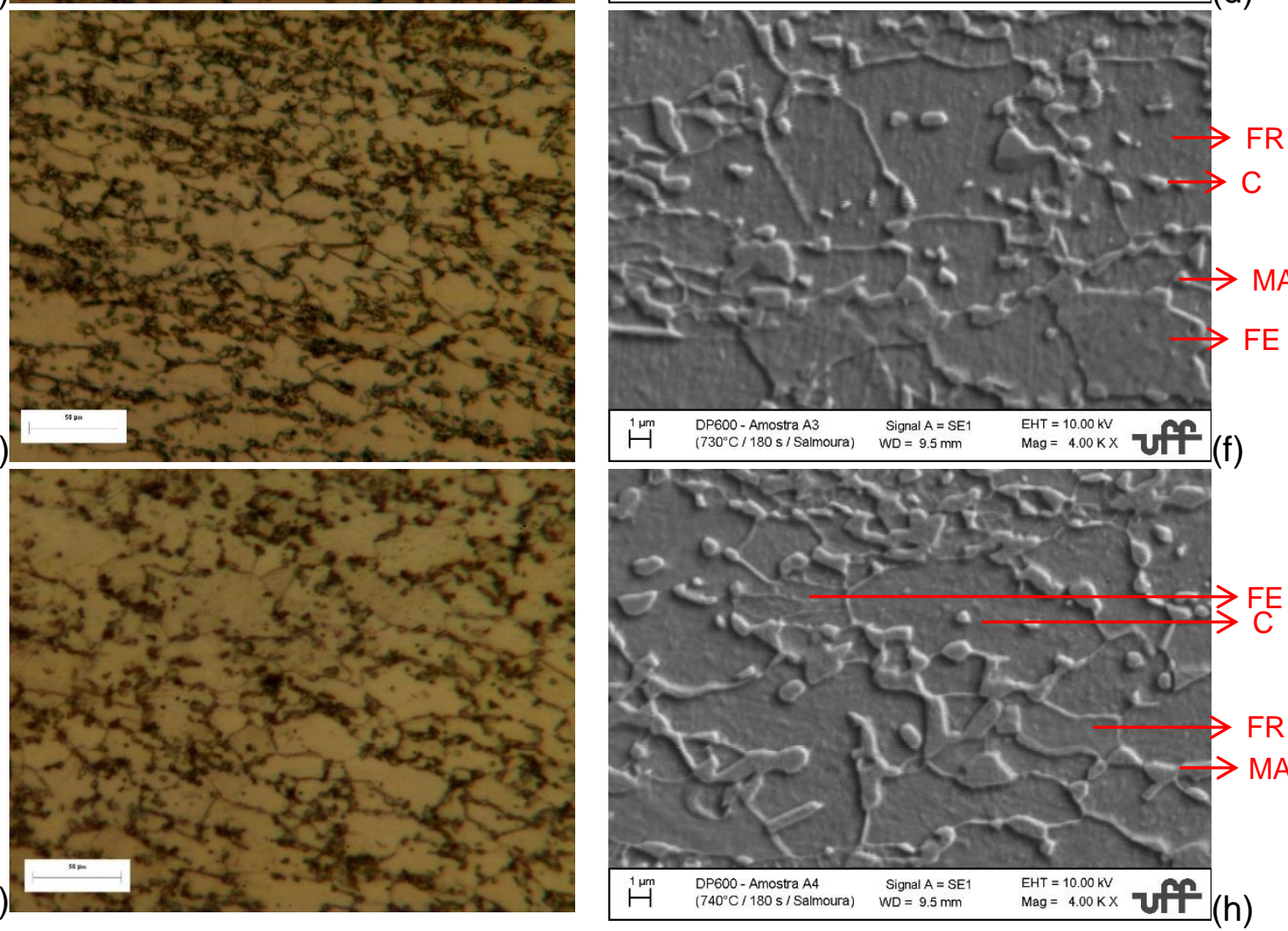

Figura 4. Aspecto microestrutural do aço em estudo após tratamento térmico com temperatura de encharque de: $(a, b) 710^{\circ} \mathrm{C}$, (c,d) $720^{\circ} \mathrm{C}$, (e,f) $730^{\circ} \mathrm{C}$, e $(\mathrm{g}, \mathrm{h}) 740^{\circ} \mathrm{C}$. Pré Ataque Nital $3 \%$, Ataque Picral envelhecido. (a,c,e,g) Aspecto geral, MO, 1000x; Ferrita - regiões claras; $2^{\mathrm{a}}$ Fase - regiões escuras. (b,d,f,h) Detalhamento, MEV, 4000x; FR - Ferrita Recristalizada; FE - Ferrita Encruada; MA - Martensita-Austenita Retida; C - Carboneto.

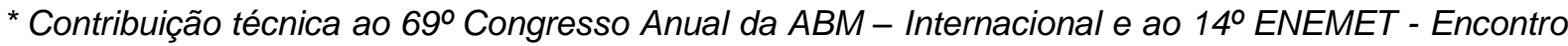
Nacional de Estudantes de Engenharia Metalúrgica, de Materiais e de Minas, 21 a 25 de julho de 2014, São Paulo, SP, Brasil. 


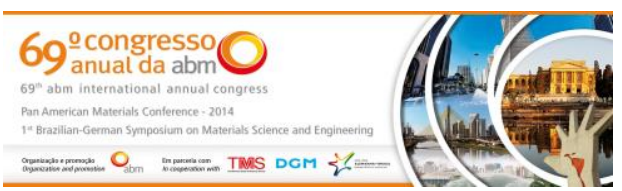

(a)

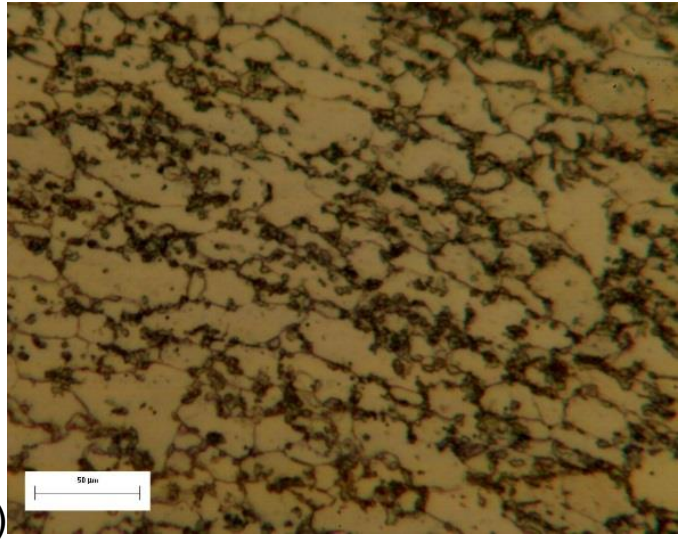

(c)

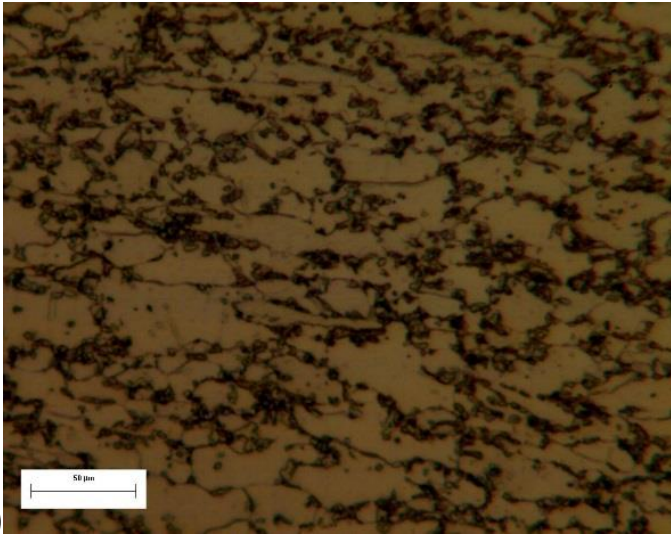

(e)
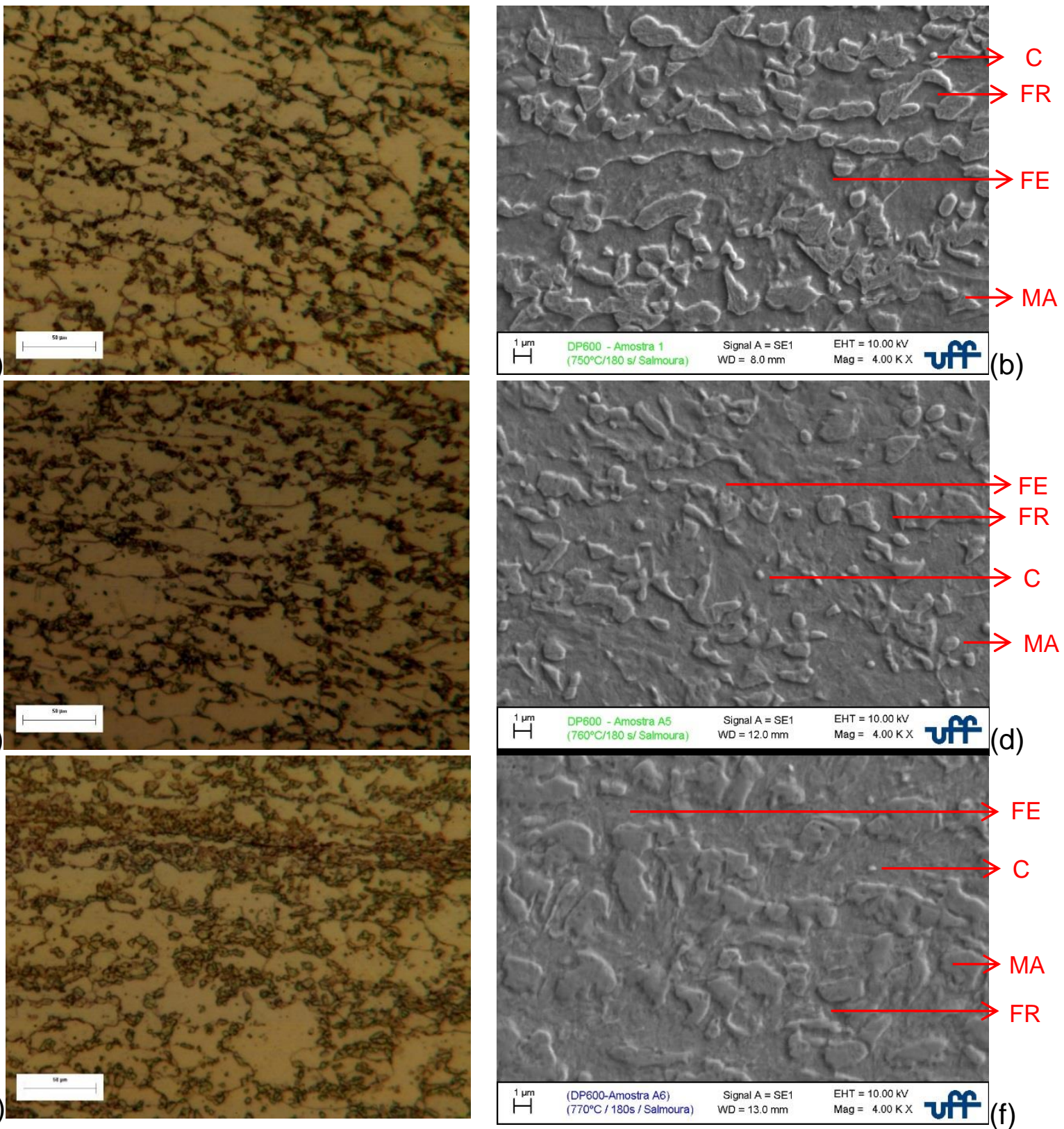

(g)
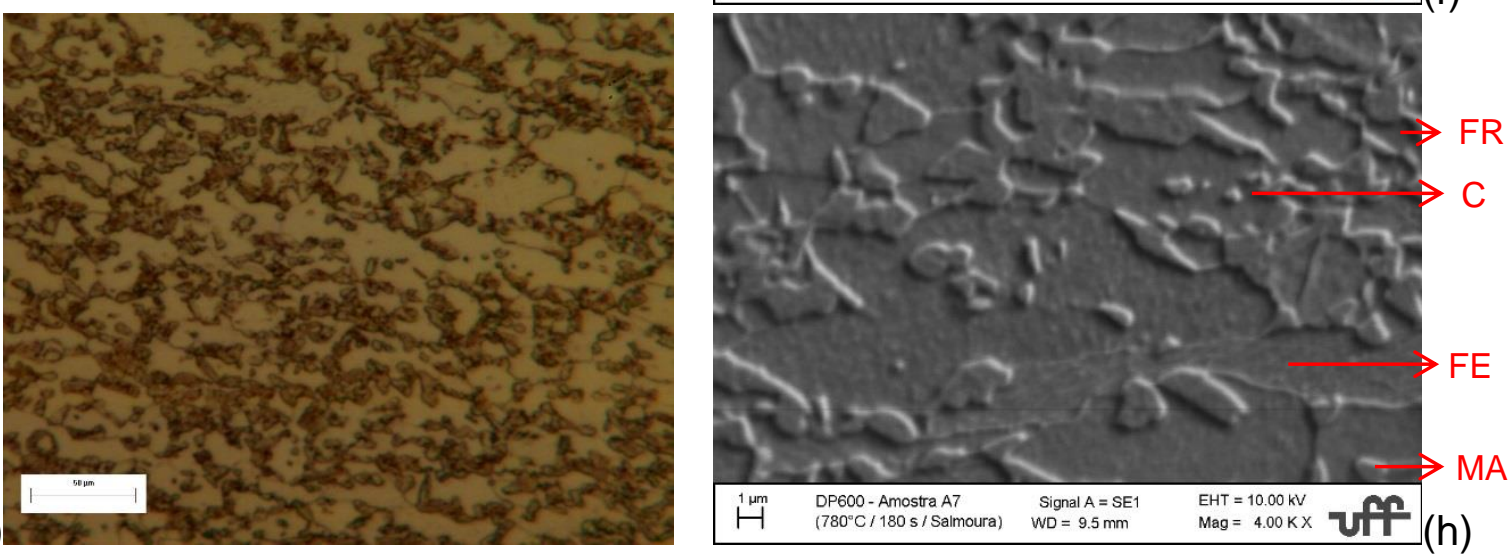

Figura 5. Aspecto microestrutural do aço em estudo após tratamento térmico com temperatura de encharque de: $(a, b) 750^{\circ} \mathrm{C}$, (c,d) $760^{\circ} \mathrm{C}$, (e,f) $770^{\circ} \mathrm{C}$, e $(\mathrm{g}, \mathrm{h}) 780^{\circ} \mathrm{C}$. Pré Ataque Nital $3 \%$, Ataque Picral envelhecido. (a,c,e,g) Aspecto geral, MO, 1000x; Ferrita - regiões claras; $2^{\mathrm{a}}$ Fase - regiões escuras. (b,d,f,h) Detalhamento, MEV, 4000x; FR - Ferrita Recristalizada; FE - Ferrita Encruada; MA - Martensita-Austenita Retida; C - Carboneto.

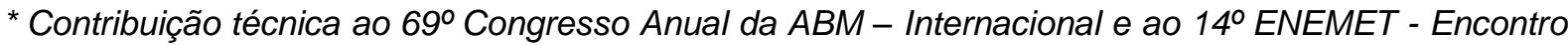
Nacional de Estudantes de Engenharia Metalúrgica, de Materiais e de Minas, 21 a 25 de julho de 2014, São Paulo, SP, Brasil. 


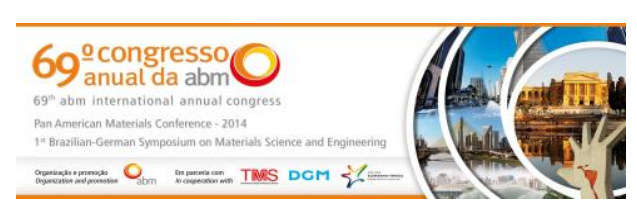

temperaturas de encharque propostas entre 710 e $800^{\circ} \mathrm{C}$, com resfriamento subsequente em salmoura. Representando assim a evolução da dureza, onde podese observar um aumento crescente da dureza em função do aumento da temperatura de encharque adotada, em conjunto com uma tendência de decréscimo do desvio padrão das medidas.

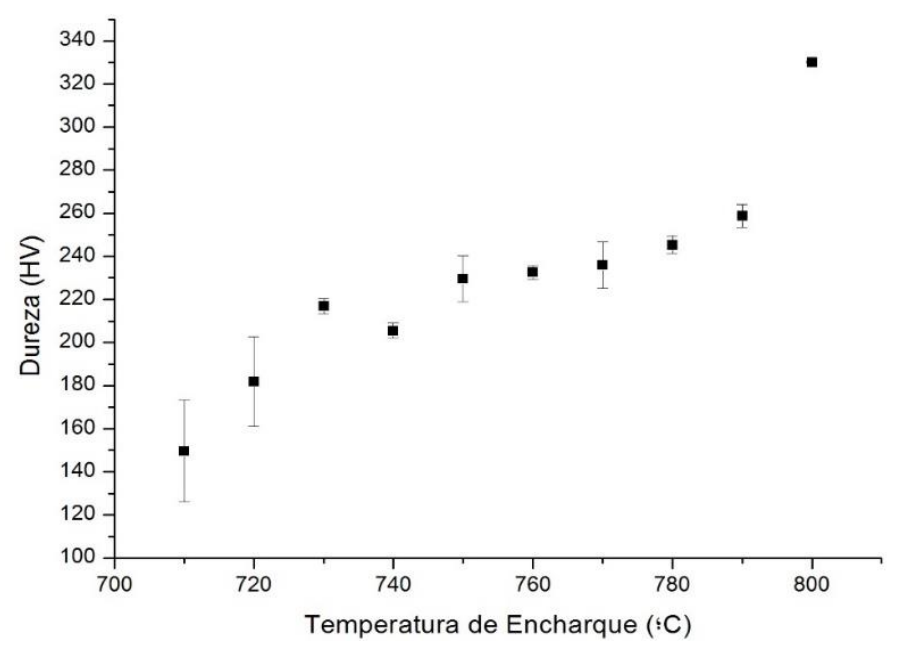

Figura 7. Evolução da dureza, valores médios e desvio padrão, em função da temperatura de encharque adotada no tratamento térmico de recozimento no campo intercrítico para o aço em estudo.

Porém pode-se observar uma redução na dureza na condição proveniente do encharque a $740^{\circ} \mathrm{C}$, quando comparada a anterior a $730^{\circ} \mathrm{C}$, comportamento este que pode estar associado a uma fração expressiva de grãos de ferrita recristalizada nesta faixa de temperatura (Figuras $4 f, h$ ), sem ser afetado de maneira significativa pelo incremento de $2^{\text {a }}$ fase (Figura 3 ). Por outro lado, no intervalo de temperatura de encharque de 750 a $770^{\circ} \mathrm{C}$ o aumento dos valores médios de dureza não tem um incremento muito significativo, sendo o desvio padrão das medidas mais alto para as amostras resultantes dos encharque a 750 e $770^{\circ} \mathrm{C}$ e os menores para o encharque a $760^{\circ} \mathrm{C}$. Comportamento este que pode estar associado ao balanço entre ao incremento da fração de grãos de ferrita recristalizada em detrimento da fração de grãos de ferrita encruada em conjunto com o incremento de $2^{\text {a }}$ fase associada ao constituinte MA (Figuras 5b,d,f). Acima de $780^{\circ} \mathrm{C}$ (Figura 7) os valores médios da dureza voltam a incrementar, tendendo o desvio padrão a manter mais baixo, fator este que deve estar associado ao incremento de constituinte MA associado ao consumo significativo dos grãos da ferrita recristalizada para formação da austenita durante 0 encharque (Figuras $5 \mathrm{~h}$ e $6 \mathrm{~b}, \mathrm{~d}$ ). Enquanto a $800^{\circ} \mathrm{C}$ a média da dureza Vickers (Figura 7) ultrapassa o valor da condição laminada a frio full hard (269 HV), comportamento este devido ao significativo incremento na fração de $2^{\text {a }}$ fase (Figura 3) associada ao constituinte MA presente em conjunto com matriz ferrítica do material (Figuras 6b,d).

\section{CONCLUSÃO}

Com base nos resultados apresentados e suporte da literatura, pode-se concluir que:

- o processo de recristalização da ferrita ocorre durante a etapa de encharque do tratamento térmico de recozimento intercrítico no intervalo de temperaturas de

\footnotetext{
* Contribuição técnica ao $69^{\circ}$ Congresso Anual da ABM - Internacional e ao 14ํㅡㄹ ENEMET - Encontro Nacional de Estudantes de Engenharia Metalúrgica, de Materiais e de Minas, 21 a 25 de julho de 2014, São Paulo, SP, Brasil.
} 


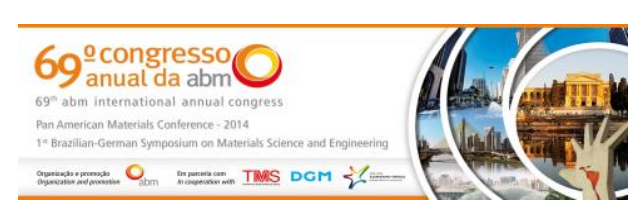

encharque propostas, porém com evidencias de encruamento até a máxima temperatura de encharque estudada $\left(800^{\circ} \mathrm{C}\right.$ por 180 segundos);

- para temperaturas de encharque acima de $740^{\circ} \mathrm{C}$, a austenita forma-se a partir da decomposição da perlita e pelo gradual consumo dos grãos da ferrita recristalizada, o que vem a contribuir para o incremento da fração de segunda fase e decréscimo do teor de carbono na austenita formada.

- Apesar do decréscimo do teor de carbono no constituinte MA, a dureza final do produto incrementa-se de maneira significativa quando de austenita formada no encharque (pela fração de $2^{a}$ fase evidenciada) ultrapassa valores próximos a $18 \%$ em conjunto com uma distribuição mais homogênea dos constituintes presentes.

\section{Agradecimentos}

Os autores agradecem a CSN por ter fornecido o material estudado, bem como por ter proporcionado meios para a realização dos tratamentos térmicos em seu Centro de Pesquisa. A UFF por ter disponibilizado os recursos utilizados na realização da caracterização microestrutural e mecânica no material. Ao Laboratório Multiusuário de Microscopia Eletrônica (LMME) da UFF pela utilização do MEV e equipamentos de preparação e análise de amostras.

\section{REFERÊNCIAS}

1 Bott IS. Tendências e Inovações em Aços. Estudo Prospectivo do Setor Siderúrgico: 2008. Brasília: Centro de Gestão e Estudos Estratégicos, ABM Rio de Janeiro 2008 44p: II.

2 Fallahi A. Microstructure-Properties Correlation of Dual Phase steels Produced by Controlled Rolling Process. Journal Materials Science and Technology. 2002;18-5:451454.

3 Ferreira FGN, Paula AS, Larcher NV, Meira RR. Influência dos Parâmetros de Recozimento Intercrítico para Obtenção de Aços Bifásicos. In: 50ํ Seminário de Laminação - Processos e Produtos Laminados e Revestidos - Internacional; 2013; Ouro Preto, Brasil. São Paulo: ABM; 2013. p.210-220.

4 Trzaska J, Dobrzanski LA. Modelling of CCT Diagrams for Engineering and Constructional Steels. Journal of Materials Processing Technology. 2007;192-193:504510.

5 Silva DC. Análise Microestrutural ao Longo do Processamento de Chapas de Aço Bifásico Galvanizado [trabalho de conclusão de curso em Engenharia Metalúrgica]. Volta Redonda: Universidade Federal Fluminense, 2013.

6 Padilha AF. Siciliano Jr F. Encruamento, Recristalização, Crescimento de Grão e Textura. São Paulo: ABM; 2005.

7 Paula AS. Caracterização Estrutural Comparativa: um Aço Extra-baixo Carbono ao Boro e um Aço Livre de Intersticiais ao Titânio [dissertação de mestrado]. Rio de Janeiro: Instituto Militar de Engenharia; 2002.

8 Mohanty RR. Girina O. Fonstein NM. Effect of Heating Rate on the Austenite Formation in Low-carbon High-Strength Steels Annealed in the Intercritical Region. Metallurgical and Materials Transactions A. 2011;42A:3680-90.

9 Olea CAW. Caracterização por Microscopia Eletrônica do Aço SAE1141 Microligado ao $\mathrm{Nb}$ [dissertação de mestrado]. Porto Alegre: Universidade Federal do Rio Grande do Sul; 2002.

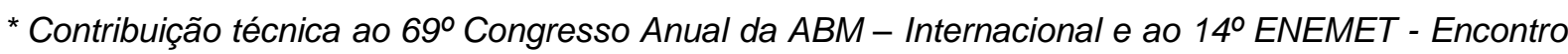
Nacional de Estudantes de Engenharia Metalúrgica, de Materiais e de Minas, 21 a 25 de julho de 2014, São Paulo, SP, Brasil.
} 